Received Date : 06-Mar-2015

Article type : Clinical Investigation

\title{
Older Adults Reporting More Diabetes Care Have Greater 9-year Survival
}

Benjamin H. Han, MD, MPH ${ }^{1}$, Caroline S. Blaum, MD, MS ${ }^{1}$, Rosie E. Ferris, MPH ${ }^{1}$, Lillian C.

Min, MD, MSHS ${ }^{2,3}$, and Pearl G. Lee, $\mathrm{MD}^{2,3}$

${ }^{1}$ Division of Geriatric Medicine and Palliative Care, Department of Medicine, New York University School of Medicine, ${ }^{2}$ Division of Geriatric and Palliative Medicine, Department of Internal Medicine, University of Michigan Medical School, Ann Arbor, ${ }^{3}$ GRECC, VA Ann Arbor Healthcare System, Ann Arbor, MI

\section{Corresponding Author:}

Benjamin H. Han, MD, MPH

New York University School of Medicine

550 First Ave., BCD615

New York, NY 10016

Phone: 646-501-9992

Fax: 646-501-2399

Benjamin.Han@nyumc.org

\section{Alternate Corresponding Author:}

Caroline S. Blaum, MD

Caroline.Blaum@nyumc.org

This is the author manuscript accepted for publication and has undergone full peer review but has not been through the copyediting, typesetting, pagination and proofreading process, which may lead to differences between this version and the Version of Record. Please cite this article as doi: $\underline{10.1111 / \text { igs.13839 }}$

This article is protected by copyright. All rights reserved 


\section{Running Head: Diabetes Care and Survival in Older AdultsABSTRACT}

Objectives: Delivery of recommended diabetes care processes has improved nationally but it is unclear if there is any association with improved survival in middle-aged and older adults with diabetes. We hypothesized that receiving more recommended diabetes care processes would translate into better 9-year survival for people in these age groups.

Design: We studied the 9-year (2002-11) mortality of adults aged $\geq 51$ years with self-reported diabetes using the Health and Retirement Study Diabetes Mailout Survey $(n=1,879)$. We dichotomized a composite measure of 5 self-reported diabetes care process measures defined as greater (3-5 processes) versus fewer ( $0-2$ processes) care processes provided.

Setting: Health and Retirement Study (HRS).

Participants: Respondents aged $\geq 51$ years $(n=1,879)$ with self-reported diabetes who completed both the Diabetes Mailout Survey and the core 2002 HRS survey.

Measurements: Cox Proportional Hazards model to test relationships between reported measures and mortality, controlling for socio-demographics, function, comorbidities, geriatric conditions, and insulin use.

Results: Baseline mean age was $68.8( \pm 8.7)$ with $26.5 \% \geq 75$ years. Prevalence of each selfreported care process was $80.1 \%, 75.9 \%, 67.5 \%, 67.7 \%$, and $48.2 \%$ for glycosylated hemoglobin testing, urine test, eye exam, aspirin counseling, and diabetes education, respectively. In 9 years, $32.1 \%$ respondents died. Greater care correlated with $24 \%$ less risk of dying (adjusted hazard ratio $[\mathrm{aHR}]=0.76,0.64-0.91)$. When respondents were age-stratified ( $\geq$ versus $<75$ years) improved survival was statistically significant only in the older age group.

Conclusion: While we are unable to account for differences in adherence to care that may also affect survival, our study demonstrates that monitoring and counseling types of diabetes care processes are associated with long-term survival benefit even among older adults aged $\geq 75$ with diabetes.

Key words: Diabetes, Older Adults, Process of Care Measures, Quality of Care

\section{INTRODUCTION}

Diabetes mellitus (DM) disproportionately affects older adults. In 2010, $27 \%$ of U.S. residents over 65 years of age had diabetes versus $8 \%$ of the overall U.S. population (1). Evidence 
suggests that cardiovascular complications of diabetes can be reduced or delayed with optimal diabetes care (2). However, care of patients with diabetes aimed at preventing complications has been inconsistent and suboptimal (3-4). In addition, the benefits of current standard diabetes care remains inconclusive for older adults, particularly after age 75.

Health care performance measures can be grouped broadly into two types: those based on recommended care-processes (i.e., whether or not care was performed by providers, for example measuring serum glycosylated hemoglobin and lipids, screening for retinopathy, counseling diet, examining feet) versus intermediate care-outcomes (i.e., whether or not targets were met for glycosylated hemoglobin, blood pressure, or lipid levels). Performance of both diabetes careprocesses and care-outcomes has improved nationally over the past decade (5-8). Recent research suggests that overly aggressive goals for intermediate outcomes among older adults may result in unintended harms (e.g., hypoglycemia) that outweigh long-term cardiovascular benefits (9-11). However, whether providing care-processes are associated with a similar harm among the very old has not been well studied, and it is still not known which older adults with comorbidities can benefit from risk factor control (12). There are no studies that directly address whether delivery of a greater number of recommended diabetes care processes is associated with survival. In this study of diabetes care processes, we studied middle-aged to older participants from the nationally representative Health and Retirement Study (HRS). We tested whether those who reported receiving a greater number of recommended diabetes care processes had better longterm survival than those who reported received fewer, and whether the association differed between those younger versus older than aged 75 years.

\section{METHODS}

We performed a nine-year follow up study using the 2003 Diabetes Mailout Survey data, a supplemental survey to the 2002 core Health and Retirement Study (HRS). The HRS (13) is a biennial health interview of community dwelling older adults living in the United States. The HRS is sponsored by the National Institute on Aging ( ) and conducted by the Institute for Social Research at the University of Michigan. Respondents are surveyed every two years in person or by phone even if living in a residential facility. If an individual is unable to complete the survey, a proxy completes it for them. To ensure the representativeness of the population 
surveyed, African American and Hispanic adults are oversampled. In contrast to most care processes studies using health-system data, the HRS DM Mailout survey is independent of participants' health insurance status.

We analyzed data from the 1,879 respondents aged 51 years and older with self-reported diabetes who completed both the Diabetes Mailout Survey and the core 2002 HRS survey. The HRS includes complete linkage with mortality data in the National Death Index on all respondents through the end of 2010, which is included in the 2013 Cross-Wave Tracker File. The HRS survival data is therefore completely ascertained (i.e., no "loss to follow-up").

The Behavioral Sciences Committee Institutional Review Board at the University of Michigan approved the HRS. The New York University School of Medicine's Institutional Review Board exempted our study from IRB review. HRS data contain no unique identifiers and are publicly available.

\section{Outcome measure}

Our outcome was time to death for each respondent, calculated as the date of death minus the date of participation in the 2002 Core Interview. As our analyses included mortality data through December 31, 2010, participants were censored if they were still alive on January 1, 2011. None of the censorings were due to dropout because there is complete data for survival outcomes in the HRS.

\section{Process of Care Measures}

In the Diabetes Mailout Survey each respondent was asked if they had received any of six diabetes care processes in the past year: a glycosylated hemoglobin A1c test (HbA1c), a urine test, a diabetes eye exam, aspirin counseling, diabetes education, and lipid profile test.

Four of the measures (HbA1c testing, urine test, eye exam, and diabetes education) were part of the initial Diabetes Quality Improvement Program (DQIP) measure set in the late 1990's (3) and current American Diabetes Association (ADA) guidelines (2), endorsed by the National Quality Forum (NQF) (14). Although now controversial, aspirin use counseling was widely recommended in $2003(3-4,6)$ including the ADA in 2003 as primary cardiovascular prevention for adults with diabetes older than age 30 (15).

Although self-report of lipid profile was part of the Diabetes Mailout Survey, we did not include this measure in the current analysis due to missing data in $10.0 \%$ of the study population (versus 
$<5 \%$ of for the other 5 measures). Other DQIP, NQF, and ADA measures such as annual foot examination and vaccinations $(2-3,14)$ were not surveyed in the Diabetes Mailout Survey. If the respondent answered, "yes" that they received the diabetes care process, then we counted that item as 1 care process provided. While the number of missing responses was low ( $<5 \%$ for any single care-process question), to reduce bias and produce the most conservative results all missing responses were presumed as not provided for that particular care process (i.e., contributed a count of zero towards the total care process score). Therefore, each respondent was considered as being eligible for 5 total care processes for this analysis. We summed the provided care processes out of a total 5 possible, then classified the respondents into two groups distinguished by the median total count: those who received less (0-2 care processes) versus those who received more recommended diabetes care processes (3-5 care processes).

\section{Co-variables}

Baseline sociodemographic and health characteristics of the respondents were assessed by the HRS 2003 Diabetes Mailout Survey and 2002 Core Interview (Table 1). Sociodemographic characteristics included age (in years), race (white versus all others), sex, education (< high school versus other), marriage status (single versus married), and net worth $(<\$ 50 \mathrm{~K}$ versus higher). Functional limitations were measured through self-reported number of both Activities of Daily Living (ADL) [bathing, walking, dressing, eating, transferring, and toileting] and Instrumental Activities of Daily Living (IADL) [meal preparation, shopping for groceries, managing medications, making telephone calls, and managing finances]. Individuals with functional limitations were defined as those having difficulty with 1 or more ADLs or IADLs. Total Illness Burden Index (TIBI) is a composite score (range 0-100) based on self-reported symptoms and diabetes-related complications developed for the HRS, was used to measure both diabetes severity and general medical comorbidity (16-18). The Diabetes Mailout Survey captured insulin use (yes/no). Five geriatric conditions (also as dichotomous variables) were surveyed in the core interview: one or more injurious falls requiring medical care in the past 2 years, urinary incontinence during the past 12 months, pain that is troublesome, poor or fair vision, and poor or fair hearing. The sixth geriatric condition, cognitive impairment, was measured by the modified Telephone Interview for Cognition Survey (TICS-m). We defined cognitive impairment if a respondent scored 11 points or worse on the 27-item TICS-m, a cutoff score that identifies mild through advanced stages of cognitive impairment (19). TICS-m 
includes multiple domains of immediate and delayed recall, working memory and mental processing speed. For each respondent, we counted the presence of each of the six geriatric condition variables, resulting in a score representing each patient's burden of geriatric conditions.

\section{Statistical Analyses}

All analyses were performed using STATA 13. Standard descriptive statistical techniques were used to determine the prevalence of process measures, socio-demographic and health covariates in the study sample, and differences in these characteristics among those missing and nonmissing for each process of care measure variable. We used visual inspection of unadjusted Kaplan-Meier survivor curves to confirm that we satisfied proportional hazard assumption over the 9-year follow up time. The survival analysis was performed using a Cox proportional hazards model comparing those provided with more recommended care (3-5 care processes) to fewer (02 care processes), with time until death as the dependent variable. Covariates (age, sex, education, marriage status, net worth, functional limitations, TIBI, insulin use, and geriatric conditions) were added in separately to assess confounding between care process scores and time until death. Only covariates with a $p<0.1$ in the univariate analyses between the two groups were selected for inclusion in subsequent multivariable modeling.

Table 2 shows the adjusted models and covariates used in the analysis. Sensitivity analyses were performed using the total care process scores as a continuous variable rather than a dichotomous grouping in the multivariable model. We also tested whether the results were sensitive to a higher cutoff determining the greater versus lesser-scoring groups (0-3 versus 4-5 care processes provided). Lastly, a separate survival analysis was performed on the entire sample stratified by age $<75$ years and $\geq 75$ years.

\section{RESULTS}

Table 1 compares demographic characteristics and health status of the two groups of respondents stratified by high versus low care process scores. At baseline, the mean age was $68.8( \pm 8.7)$, $52.4 \%$ female, $68.5 \%$ of the sample were white, and $21.9 \%$ on insulin. The prevalence of selfreported process of care measures were $80.1 \%, 75.9 \%, 67.5 \%, 67.7 \%$, and $48.2 \%$ for $\mathrm{HbA} 1 \mathrm{c}$ 
test, urine test, eye exam, aspirin counseling, and diabetes education, respectively. Of the 1,879 participants, $73.8 \%$ reported receiving 3-5 process measures.

Those reported receiving more care processes (3-5 care processes) were more likely to be younger $(68.7 \pm 8.4$ versus $69.2 \pm 9.3, \mathrm{p}=0.03)$, be male $(49.0 \%$ versus $43.8 \%, \mathrm{p}=0.05)$, be married $(68.5 \%$ versus $61.3 \%, \mathrm{p} \leq 0.01)$, have more education $(67.5 \%$ at least high school graduates versus $57.0 \%, \mathrm{p} \leq 0.01)$, have higher net worth $(70.7 \%$ versus $60.4 \%$ net worth $>\$ 50 \mathrm{~K}$, $\mathrm{p} \leq 0.01$ ), use insulin ( $24.1 \%$ versus $15.6 \%, \mathrm{p} \leq 0.01$ ), and have less impairment in cognition ( $25.6 \%$ versus $34.5 \%, \mathrm{p}=<0.01)$, vision $(25.5 \%$ versus $33.7 \%, \mathrm{p} \leq 0.01)$. Those with more care processes also had a lower mean of the six geriatric conditions [1.40 (1.33-1.46) versus 1.56 (1.44-1.67), $\mathrm{p}=0.016]$, but a higher mean TIBI score [36.67 (17.7-55.64) versus 34.06 (15.5552.57), $\mathrm{p} \leq 0.01]$.

Time to death or right-censoring ranged from 0.25 to 9.08 years. In 9 years (2002-2011), 32.1\% (604) respondents died. Those with better care were more likely to be alive at the end of the study period (January 1, 2011) [69.1\% versus 64.3\%, p=0.05]. Figure 1 is the unadjusted survival analysis curves for the two groups, and found to be statistically different by the log rank test $(\mathrm{p}=0.025)$. The hazard ratio (HR), before adjusting for covariates, was 0.82 [95\% CI 0.690.98], in favor of the group that received more recommended care processes. For 14 of 1879 respondents $(0.7 \%)$, one or more co-variables were missing, so the final multivariable analysis was performed on 1865 respondents with complete information (Figure 2). After inclusion of covariates that were significant in bivariate analysis (i.e. in model 5 that adjusted for age, sex, marital status, net worth, education, physical function, geriatric conditions, TIBI, and insulin use) the HR for greater care process increased in protectiveness to 0.76 [0.64-0.91] (Table 2). When the final multivariable model was stratified by age $\geq 75$ versus $<75$, the percent of patients who died was $57.2 \%$ in the older group and $23.1 \%$ in the younger group. The effect of being in the group receiving greater diabetes care processes was stronger and more statistically significant in the older group (HR of 0.72 [95\% CI 0.55-0.93]) compared to the younger group (HR of 0.84 [0.65-1.09] (Table 3). Sensitivity analyses using process of care measures as a continuous variable in the multivariable model as well as using different dichotomized care process groups (0-3 measures) versus (4-5 measures) gave comparable findings. 


\section{DISCUSSION}

Diabetes care process measures were developed to improve the quality of diabetes care and to improve health outcomes (3). In this nationally representative sample of middle-aged and older Americans with diabetes we found that respondents who reported receiving a greater number of 5 selected diabetes care process measures had significantly better survival over 9 years of followup. This association was independent of age, sex, socioeconomic status, demographics, functional health, geriatric conditions, insulin use, and diabetes illness burden. More importantly, we demonstrated in a relatively small subsample of older respondents aged 75 and older that basic, non-aggressive care processes such as counseling and monitoring are not harmful and seem to continue to be associated with benefit.

It is important to note that our results focus on diabetes monitoring and counseling-type care processes, rather than achievement of intermediate outcomes such as glycemic targets. The care processes we studied are distinct from those recommended to achieve glycemic targets, such as prescribing of hypoglycemic and antihypertensive medications (7-10, 20). Therefore we believe that our results do not contradict recent research suggesting that aggressive glycemic and blood pressure control in older adults appear to have diminishing marginal benefits and even harm compared to patients prescribed more modest targets (21-23).

Our results should be viewed in light of prior research on the long-term outcomes of care processes provided to non-geriatric populations of adults with diabetes. A systematic review (24) examining care processes for adults with diabetes, many on a practice systems level, found no association with hospitalizations, vascular complications, and death. The authors concluded that there is insufficient evidence that diabetes process measures, particularly those focused on tests performed, predict patient outcomes (24). Two large observational studies based in Italy have focused on composite scores of diabetes care. The first, a study of over 3,000 patients from 101 diabetes clinics in Italy, found no relationship between a comprehensive set of care processes measured by medical record review and 5-year survival (25). The second was a study of over 5000 patients in 62 clinics that found better care processes were associated with a lower risk of cardiovascular events over a median follow-up of 28 months (26), but was not statistically significant for survival.

In contrast, our results did find a relationship with survival. The reason may be due to the older age of our sample, resulting in an increase mortality rate in general, therefore affording better 
power for detecting associations. One other study of older adults, Assessing the Care of Vulnerable Elders study, also reported that composite care process measures (including but not limited to diabetes care processes) measured by chart review in older US community-dwelling primary care patients are associated with short-term survival and better functional status (27-28), independent of age at baseline.

The currently endorsed NQF comprehensive diabetes care measures only apply until the age of 75 (14), consistent with the upper age-limit of many clinical trials (29). However, the heterogeneity of the older diabetes population and implications for appropriateness of care has received increasing attention (9). Guidelines such as those endorsed by the American Geriatrics Society and the ADA now support tailoring glycemic and blood pressure targets according to an older individual's functional status and life expectancy $(2,9)$. Our findings suggest that this approach may also feasibly be extended for diabetes care process measures. We found that there continued to be a survival benefit associated with monitoring and counseling-type processes after age 75 . The reason may be due to increased mortality in general, with age, therefore, resulting in greater power to detect a benefit in our older compared to younger participants. Therefore, for people above age 75 with functional independence and a reasonable life expectancy, our results suggest that providing these types of less-burdensome care processes may be appropriate. This study does have notable strengths. Because the HRS is US population-based, rather than a study conducted within a particular health care setting or health insurance plan, our results offer a perspective that prior studies could not. We were also able to control for aspects of illness that many other studies cannot, including functional status, two types of comorbidity (the TIBI and the count of geriatric conditions), cognitive status, and socioeconomic status. Since care processes are unlikely to be ever be studied as a controlled trial, population-based observational studies are necessary, but most datasets do not include any of these co-variables. The opportunity to follow patients of advanced age longitudinally for 9 years is also unique in this field.

Although we found a statistical association between providing recommended care and survival, these results do not suggest a mechanism. The relationship may be related to unmeasured patient characteristics or behaviors, and/or how physicians provide care to specific patients. It is possible that reduced care is acting as a marker for other prognostic factors, such as reduced adherence to recommended care or poor access to care, which are known to be associated with poor glycemic and blood pressure control (30). While these factors are not directly measured in our study, our 
adjustment for demographics and socioeconomic status should partially account for these differences. Physicians may be providing more care to people who appear healthier and/or more functionally independent, beyond what we could control for with the data we had available. On the other hand, it has been found that some patients with more chronic disease receive more care presumably because of more frequent interactions with physicians (31) and our data are consistent with this.

In our analyses, we included common confounders of process and outcome, namely income and education, the TIBI (a measure of co-morbidity and symptoms) and functional status. Such measures were previously found to predict survival (32-33). However, clinical or social complexity was likely under measured. There are further unmeasured confounders that deserve future research. For instance, our care process measures may have indirectly accounted for individual's access to care, self-efficacy or better self-care, and adherence to care, which was the reason for improved survival. A previous study has shown that the number of diabetes care processes may be associated with patient satisfaction measures and self-rated quality of diabetes care (20), which could in turn influence survival. Future studies examining access to care, selfefficacy, self-care, and adherence and their relationship with both process measures and survival are needed.

This study has several other limitations. First, our analysis was limited to adults with a selfreported diagnosis of diabetes and of receiving process of care measures. Problems with selfreported data include recall bias and social-desirability bias. Although we did not have access to medical records, which is considered to be a more accurate way to capture care processes, our study sheds some light onto patient-perceived receipt on care. Patient interview is considered to be a valid way to capture counseling-type care processes (34). Second, our analysis only included the five process measures that were reliably available in the HRS data, and did not include several important measures of diabetes quality of care such as foot examinations, smoking cessation counseling, vaccinations, or blood pressure and lipid targets (2-3, 14). Further, the HRS question for proteinuria was worded simply to facilitate respondent comprehension as a "urine test" - therefore potentially introducing misclassification if patients recalled any other urine test mistakenly for urine protein testing. However, we do not believe that this misclassification would have biased our results since sicker patients with need for other types of urine tests would not be expected to have better survival. Third, over the past two 
decades the process of care measures have evolved. In 2003 when the HRS mailout was performed, the recommendation from the ADA was to consider aspirin therapy to people with diabetes for primary cardiovascular prevention for "high-risk adults", which included anyone over the age of 30 (15). However now the ADA recommends aspirin for primary cardiovascular prevention for those at increased cardiovascular risk profiles aside from age (2), and American Geriatrics Society has recommended caution due to insufficient evidence for supporting aspirin for primary cardiovascular prevention (9). Despite current uncertainty, in 2003 aspirin counseling was recommended (15) and therefore reflects quality care as part of diabetes care processes at that time. Fourth, the survey measured care processes delivered at only one point in time (one year prior to the mailout), therefore we presume that the effect on survival did not vary with time over the next 9 years. Quality of care may change, for example, as a result of interventions designed to reduce variation in care by targeting patients with the worst care. However, we expect that any such secular changes would result in less variation in our predictor variable and therefore bias our results towards finding no difference. Finally, our study was not designed to study the association of each individual care process with survival. Composite scores have been thought to improve the reliability for evaluations of quality compared to single measures (6), but it is possible that different methods of composite scores would give different results. However, sensitivity analyses using different composite cut points of 0-3 versus 4-5 measures and using care processes as a continuous variable resulted in similar findings. Nevertheless, our results should not be interpreted as evidence in support of any particular care process.

In conclusion, we found in a nationally representative sample, that individuals receiving better diabetes care as measured by receipt of care processes had better survival, and that this association is observable even among individuals aged 75 and older. Current care process measures end eligibility at age 75 , but this study suggests that further research is needed to consider whether some older adults should continue to be appropriate for certain care process measures, such as those with reasonable life expectancies. Our findings suggest that age alone should not exclude older adults with diabetes from having their quality of diabetes counseling and monitoring assessed. 


\section{ACKNOWLEDGMENTS}

Poster Presentation: Blaum, C.S., Ferris, R. Han, B., Min, L. \& Lee, P. Self-Reported Diabetes Process of Care Measures Predict 9-Year Survival. Poster presented at the American Geriatrics Society (AGS) Annual Meeting, Orlando, FL, May, 2014.

Funding Source: University of Michigan Claude D Pepper Older American Independence Center (AG024824), John A. Hartford Foundation Center of Excellence National Program and the Peter S. Sharpe Foundation.

Conflict of Interest: The editor in chief has reviewed the conflict of interest checklist provided by the authors and has determined that the authors have no financial or any other kind of personal conflicts with this paper.

Author Contributions: Benjamin H. Han: researched data and wrote the manuscript. Lillian C. Min: researched data and reviewed/edited the manuscript. Caroline S. Blaum: researched data and reviewed/edited the manuscript. Rosie E. Ferris: researched data and reviewed/edited the manuscript. Pearl G. Lee: researched data and reviewed/edited the manuscript.

\section{Sponsor's Role: None}

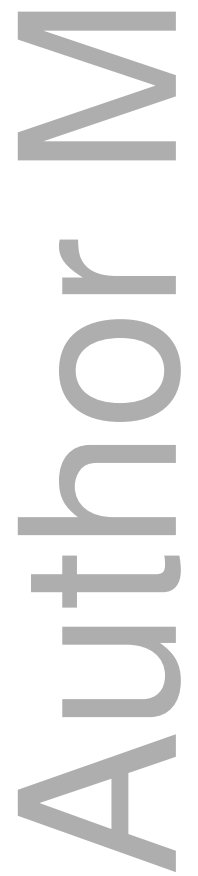




\section{REFERENCES}

1. Centers for Disease Control and Prevention. National diabetes fact sheet: national estimates and general information on diabetes and prediabetes in the United States, 2011. Atlanta, GA: U.S. Department of Health and Human Services, Centers for Disease Control and Prevention, 2011.

2. American Diabetes Association. Standards of Medical Care in Diabetes--2014. Diabetes Care 2013;37 (Suppl 1):S14-S80.

3. Fleming BB, Greenfield S, Engelgau MM et al. The Diabetes Quality Improvement Project: moving science into health policy to gain an edge on the diabetes epidemic. Diabetes Care 2001;24:1815-1820.

4. Saaddine JB, Engelgau MM, Beckles GL et al. A diabetes report card for the United States: Quality of care in the 1990s. Ann Intern Med 2002;136:565-574.

5. Sawin CT, Walder DJ, Bross DS et al. Diabetes process and outcome measures in the Department of Veterans Affairs. Diabetes Care 2004;27 (Suppl 2):B90-B94.

6. O'Connor PJ,Bodkin NL, Fradkin J et al. Diabetes Performance Measures: Current Status and Future Directions. Diabetes Care 2011;34:1651-1659.

7. Saaddine JB, Cadwell B, Gregg EW et al. Improvements in diabetes processes of care and intermediate outcomes: United States, 1988-2002. Ann Intern Med 2006;144:465-474.

8. Ali MK, Bullard KM, Saaddine JB et al. Achievement of Goals in U.S. Diabetes Care, 19992010. N Engl J Med 2013;368:1613-1624.

9. American Geriatrics Society Expert Panel on the Care of Older Adults with Diabetes Mellitus. Guidelines Abstracted from the American Geriatrics Society Guidelines for Improving the Care of Older Adults with Diabetes Mellitus: 2013 Update. J Am Geriatr Soc 2013;61:2020-2026.

10. Lee SJ, Eng C. Goals of Glycemic Control in Frail Older Patients With Diabetes. JAMA.2011;305(13):1350-1351.

11. Tinetti ME, Han L, Lee DH et al. Antihypertensive Medications and Serious Fall Injuries in a Nationally Representative Sample of Older Adults. JAMA Intern Med 2014;174:588-595.

12. Pearte CA, Furberg CD, O'Meara ES et al. Characteristics and baseline predictors of future fatal versus nonfatal coronary heart disease events in older adults: The Cardiovascular Health Study. Circulation 2006;113:2177-2185. 
13. Juster FT, Suzman R. An overview of the Health and Retirement Study. J Hum Res 1995;30:S7-S56.

14. Comprehensive Diabetes Care (Composite Measure). National Quality Forum Web site. http://www.qualityforum.org/QPS. Accessed November 1, 2014.

15. Colwell JA, American Diabetes Association. Aspirin therapy in diabetes. Diabetes Care. 2003;27 Suppl 1:S72-S73.

16. Greenfield S, Sullivan L, Dukes KA et al. Development and testing of a new measure case mix for use in office practice. Med Care 1995;33(Suppl): AS47-AS55.

17. Kaplan SH, Greenfield S, Gandek B et al. Characteristics of physicians with participatory decision- making styles. Ann Intern Med 1996;124:497- 504.

18. Heisler M, Cole I, Weir D et al. Does physician communication influence older patients' diabetes self-management and glycemic control? Results from the Health and Retirement Study (HRS). J Gerontol A Biol Sci Med Sci 2007;62:1435-1442.

19. de Jager CA, Budge MM, Clarke R. Utility of TICS-M for the assessment of cogitive function in older adults. Int J Geriatr Psychiatry 2003;18:318-324.

20. Ackermann RT. Is the Number of Documented Diabetes Process-of-Care Indicators Associated With Cardiometabolic Risk Factor Levels, Patient Satisfaction, or Self-Rated Quality of Diabetes Care?: The Translating Research into Action for Diabetes (TRIAD) study. Diabetes Care 2006;29:2108-2113.

21. Greenfield S, Billimek J, Pellegrini F, et al. Comorbidity affects the relationship between glycemic control and cardiovascular outcomes in diabetes: A cohort study. Ann Intern Med 2009; 151:854-860.

22. Ismail-Beigi F, Craven T, Banerji MA et al. Effect of intensive treatment of hyperglycaemia on microvascular outcomes in type 2 diabetes: An analysis of the ACCORD randomised trial. Lancet 2010;376: 419-430.

23. Vijan S, Sussman JB, Yudkin JS et al. Effect of patients' risks and preferences on health gains with plasma glucose level lowering in type 2 diabetes mellitus. JAMA Intern Med 2014; 174:1227-1234.

24. Sidorenkov G, Haaijer-Ruskamp FM, de Zeeuw D et al. Relation between quality-of-care indicators for diabetes and patient outcomes: A systematic literature review. Med Care Res Rev 2011;68:263-289. 
25. De Berardis G, Pellegrini F, Franciosi M et al. QuED (Quality of Care and Outcomes in Type 2 Diabetes) Study Group Quality of diabetes care predicts the development of cardiovascular events: Results of the QuED study. Nutr Metab Cardiovasc Dis 2008;18:57-65

26. Rossi MC, Lucisano G, Comaschi M et al. Quality of diabetes care predicts the development of cardiovascular events: Results of the AMD-QUASAR study. Diabetes Care 2011;34:347352.

27. Higashi T, Shekelle PG, Adams JL et al. Quality of care is associated with survival in vulnerable older patients. Ann Intern Med 2005;143:274-281.

28. Min L, Reuben D, Karlamangla A et al. Abbreviated care-process quality indicator sets linked with survival and functional status benefit in older adults under ambulatory care. J Am Geriatr Soc 2014; 62:1442-1450.

29. Zulman DM, Sussman JB, Chen X et al. Examining the evidence: A systematic review of the inclusion and analysis of older adults in randomized controlled trials. J Gen Intern Med 2011;26:783-790.

30. Zhang X, Bullard KM, Gregg EW et al. Access to health care and control of ABCs of diabetes. Diabetes Care. 2012;35:1566-1571.

31. Bae S, Rosenthal MB. Patients with multiple chronic conditions do not receive lower quality of preventive care. J Gen Intern Med 2008; 23: 1933-1939.

32. Blaum C, Cigolle CT, Boyd C et al. Clinical complexity in middle-aged and older adults with diabetes: The Health and Retirement Study. Med Care 2010;48:327-334.

33. Cigolle CT, Kabeto MU, Lee PG et al. Clinical complexity and mortality in middle-aged and older adults with diabetes. J Gerontol A Biol Sci Med Sci 2012;67:1313-1320.

34. Wenger NS, Solomon DH, Roth CP et al. The quality of medical care provided to vulnerable community-dwelling older patients. Ann Intern Med. 2003;139:740-747.

This article is protected by copyright. All rights reserved 


\section{GRAPHICS}

\begin{tabular}{|c|c|c|c|c|}
\hline $\begin{array}{l}\text { Characterstics } \\
(\text { Column \%) }\end{array}$ & $\begin{array}{l}\text { All \% (n) } \\
(n=1,879)\end{array}$ & $\begin{array}{l}\text { 0-2 Process of } \\
\text { Care Measures } \\
\%(n)(n=493)\end{array}$ & $\begin{array}{l}\text { 3-5 Process of } \\
\text { Care Measures } \\
\%(n)(n=1,386)\end{array}$ & $\begin{array}{l}\text { 0-2 measures vs. } \\
\text { 3-5 measures } \\
\text { P-values }\end{array}$ \\
\hline Age (Years) & $68.8 \pm 8.7$ & $69.2 \pm 9.3$ & $68.7 \pm 8.4$ & 0.027 \\
\hline $51-64$ & $34.4(n=646)$ & $35.9(n=177)$ & $33.8(n=469)$ & \\
\hline $65-74$ & $39.1(n=735)$ & $34.3(n=169)$ & $40.8(n=566)$ & \\
\hline$\geq 75$ & $26.5(n=498)$ & $29.8(n=147)$ & $25.4(n=351)$ & \\
\hline Sex & & & & 0.05 \\
\hline Female & $52.4(n=984)$ & $56.2(n=277)$ & $51.0(n=707)$ & \\
\hline Race & & & & 0.5 \\
\hline White & $68.5(n=1,288)$ & $65.3(n=322)$ & $69.7(n=966)$ & \\
\hline Black (19.5\%) & $19.5(n=367)$ & $19.7(\mathrm{n}=97)$ & $19.5(n=270)$ & \\
\hline Hispanic $(10.7 \%)$ & $10.7(n=201)$ & $13.0(\mathrm{n}=64)$ & $9.9(n=137)$ & \\
\hline Other $(1.2 \%)$ & $1.2(n=23)$ & $2.0(\mathrm{n}=10)$ & $0.9(n=13)$ & \\
\hline Education & & & & $<0.01$ \\
\hline$<12$ grade $(35.15 \%)$ & $35.1(n=659)$ & $42.8(n=211)$ & $32.3(n=448)$ & \\
\hline 12th grade $(33.12 \%)$ & $33.1(n=621)$ & $30.4(n=150)$ & $34.0(n=471)$ & \\
\hline$>12$ grade $(31.73 \%)$ & $31.7(n=595)$ & $26.6(n=131)$ & $33.5(n=464)$ & \\
\hline Married $(66.58 \%)$ & $66.6(n=1,251)$ & $61.3(n=302)$ & $68.5(n=949)$ & $<0.01$ \\
\hline Net worth & & & & $<0.01$ \\
\hline$<\$ 50 \mathrm{k}$ & $32.0(n=601)$ & $39.6(n=195)$ & $29.3(n=406)$ & \\
\hline$\$ 50 \mathrm{k}-\$ 535 \mathrm{k}$ & $55.6(n=1,044)$ & $50.3(n=248)$ & $57.4(n=796)$ & \\
\hline$>\$ 535 \mathrm{k}$ & $12.5(n=234)$ & $10.1(\mathrm{n}=50)$ & $13.3(n=184)$ & \\
\hline $\mathbf{A D L} \dagger$ & & & & 0.09 \\
\hline 0 ADL Difficulties & $75.2(n=1,413)$ & $72.8(\mathrm{n}=359)$ & $76.1(n=1,054)$ & \\
\hline 1-3 ADL Difficulties & $20.7(n=389)$ & $21.5(n=106)$ & $20.4(n=283)$ & \\
\hline 4-6 ADL Difficulties & $4.1(n=77)$ & $5.7(\mathrm{n}=28)$ & $3.5(n=49)$ & \\
\hline IADL* & & & & 0.07 \\
\hline 0 IADL Difficulties & $80.3(n=1,508)$ & $79.7 \%(n=393)$ & $80.5(n=1,115)$ & \\
\hline 1-2 IADL Difficulties & $13.4(\mathrm{n}=251)$ & $12.0(\mathrm{n}=59)$ & $13.9(n=192)$ & \\
\hline
\end{tabular}

This article is protected by copyright. All rights reserved 


\begin{tabular}{|l|l|l|l|l|}
\hline 3-5 IADL Difficulties & $6.3(\mathrm{n}=118)$ & $8.3(\mathrm{n}=41)$ & $5.6(\mathrm{n}=77)$ & \\
\hline TIBI (Mean) & $35.98( \pm 18.88)$ & $34.06( \pm 18.51)$ & $36.67( \pm 18.97$ & $<0.01$ \\
\hline Geriatric Conditions & & & & 0.016 \\
\hline Injurious Falls & $6.2(\mathrm{n}=117)$ & $6.1(\mathrm{n}=30)$ & $6.3(\mathrm{n}=87)$ & 0.88 \\
\hline Cognitive Impairment & $27.9(\mathrm{n}=525)$ & $34.5(\mathrm{n}=170)$ & $25.6(\mathrm{n}=355)$ & $<0.01$ \\
\hline Pain & $36.6(\mathrm{n}=687)$ & $34.7(\mathrm{n}=171)$ & $37.2(\mathrm{n}=516)$ & 0.33 \\
\hline Urinary Incontinence & $21.2(\mathrm{n}=399)$ & $21.5(\mathrm{n}=106)$ & $21.1(\mathrm{n}=293)$ & 0.85 \\
\hline Hearing Impairment & $24.6(\mathrm{n}=462)$ & $24.8(\mathrm{n}=122)$ & $24.5(\mathrm{n}=340)$ & 0.89 \\
\hline Visual Impairment & $27.6(\mathrm{n}=519)$ & $33.7(\mathrm{n}=166)$ & $25.5(\mathrm{n}=353)$ & $<0.01$ \\
\hline Insulin Use & $21.9(\mathrm{n}=411)$ & $15.6(\mathrm{n}=77)$ & $24.1(\mathrm{n}=334)$ & $<0.01$ \\
\hline Vital Status 2010 & & & & \\
\hline Alive & $67.9(\mathrm{n}=1,275)$ & $64.3(\mathrm{n}=317)$ & $69.1(\mathrm{n}=958)$ & 0.05 \\
\hline
\end{tabular}

$\uparrow$ ADL- Activities of Daily Living, *IADL - Instrumental Activities of Daily Living, $\ddagger$ TIBI -

Total Illness Burden Index

\begin{tabular}{|c|c|c|c|c|c|}
\hline Variable & $\begin{array}{l}\text { Model 1: } \\
\text { Unadjusted } \\
(\mathbf{n = 1 , 8 7 9 )} \\
\\
\end{array}$ & $\begin{array}{l}\text { Model 2: Age- } \\
\text { Adjusted } \\
(n=1,879)\end{array}$ & $\begin{array}{l}\text { Model 3: Model } \\
2+ \\
\text { Demographic } \\
\text { \& SES } \\
(n=1,875)\end{array}$ & $\begin{array}{l}\text { Model 4: } \\
\text { Models } 2 \text { \& } 3 \text { + } \\
\text { Functional } \\
\text { Health } \\
(\mathrm{n}=1,873)\end{array}$ & $\begin{array}{l}\text { Model 5: } \\
\text { Models 2, } 3 \text { \& } 4 \\
+ \\
\text { Comorbidities } \\
\text { and Insulin Use } \\
(n=1,865)\end{array}$ \\
\hline $\begin{array}{l}\text { Process of } \\
\text { Care } \\
\text { Measures } \dagger\end{array}$ & $0.82(0.69-0.98)^{*}$ & $0.84(0.70-0.997)^{*}$ & $0.87(0.73-1.03)$ & $0.84(0.70-1.00)^{*}$ & $\begin{array}{l}0.76(0.64- \\
0.91)^{*}\end{array}$ \\
\hline Age 65-74 & & $1.65(1.31-2.07)^{*}$ & $1.61(1.28-$ & $1.62(1.29-2.04)^{*}$ & $1.70(1.35-$ \\
\hline
\end{tabular}




\begin{tabular}{|c|c|c|c|c|c|}
\hline & & & $2.03)^{*}$ & & $2.15)^{*}$ \\
\hline$\geq 75$ & & $4.31(3.47-5.35)^{*}$ & $\begin{array}{l}4.10(3.29- \\
5.12)^{*}\end{array}$ & $3.90(3.12-4.87)^{*}$ & $\begin{array}{l}4.53(3.59- \\
5.72)^{*}\end{array}$ \\
\hline Female & & & $\begin{array}{l}0.73(0.61- \\
0.87)^{*}\end{array}$ & $0.70(0.60-0.84)^{*}$ & $\begin{array}{l}0.69(0.57- \\
0.82)^{*}\end{array}$ \\
\hline Less than HS & & & $\begin{array}{l}1.19(1.00- \\
1.41)^{*}\end{array}$ & $1.10(0.93-1.31)$ & $1.03(0.86-1.23)$ \\
\hline Single & & & $\begin{array}{l}1.28(1.06- \\
1.54)^{*}\end{array}$ & $1.24(1.03-1.50)^{*}$ & $\begin{array}{l}1.26(1.04- \\
1.51)^{*}\end{array}$ \\
\hline$<50 \mathrm{k}$ & & & $\begin{array}{l}1.70(1.24- \\
2.33)^{*}\end{array}$ & $1.43(1.04-1.97) *$ & $1.29(0.93-1.78)$ \\
\hline 50-535k & & & $\begin{array}{l}1.46(1.09- \\
1.96)^{*}\end{array}$ & $1.42(1.07-1.90)^{*}$ & $\begin{array}{l}1.35(1.00- \\
1.80)^{*}\end{array}$ \\
\hline $\begin{array}{l}1 \text { or More } \\
\text { ADL }\end{array}$ & & & & $1.30(1.07-1.58)^{*}$ & $1.14(0.93-1.40)$ \\
\hline $\begin{array}{l}1 \text { or More } \\
\text { IADL }\end{array}$ & & & & $1.99(1.63-2.43)^{*}$ & $\begin{array}{l}1.82(1.49- \\
2.24)^{*}\end{array}$ \\
\hline $\begin{array}{l}\text { Geriatric } \\
\text { Conditions }\end{array}$ & & & & & $1.01(0.93-1.09)$ \\
\hline Uses Insulin & & & & & $\begin{array}{l}1.21(1.00- \\
1.46)^{*}\end{array}$ \\
\hline TIBI & & & & & $\begin{array}{l}1.01(1.01- \\
1.02)^{*}\end{array}$ \\
\hline
\end{tabular}

†Process of Care measures include HbA1c test, urine test, eye exam, aspirin counseling, and diabetes education $(0=0-2,1=3-5),{ }^{*}$ Significant $\mathrm{P}$-Value

\begin{tabular}{|c|c|c|c|c|}
\hline+2 & & 75 & & $\geq 75$ \\
\hline Variable & $\begin{array}{l}\text { Model 1: } \\
\text { Unadjusted } \\
(\mathrm{n}=1, \mathbf{3 8 1})\end{array}$ & $\begin{array}{l}\text { Model 5: Models } \\
2,3 \& 4+ \\
\text { Comorbidities }\end{array}$ & $\begin{array}{l}\text { Model 1: } \\
\text { Unadjusted } \\
(n=498)\end{array}$ & $\begin{array}{l}\text { Model 5: Models 2, } 3 \\
\text { \& } 4 \text { + Comorbidities } \\
(n=493)\end{array}$ \\
\hline
\end{tabular}

This article is protected by copyright. All rights reserved 


\begin{tabular}{|l|l|l|l|l|}
\hline & & $(\mathbf{n}=1,372)$ & & \\
\hline $\begin{array}{l}\text { Process of Care } \\
\text { Measures }+\end{array}$ & $0.88(0.69-1.13)$ & $0.84(0.65-1.09)$ & $0.82(0.64-1.06)^{*}$ & $0.72(0.55-0.93)^{*}$ \\
\hline Female & & $0.64(0.51-0.82)^{*}$ & & $0.69(0.52-0.90)^{*}$ \\
\hline Less than HS & & $1.14(0.89-1.45)$ & & $0.98(0.76-1.28)$ \\
\hline Single & $1.31(1.01-1.70)^{*}$ & & $1.27(0.96-1.67)$ \\
\hline$<50 k$ & $1.10(0.71-1.70)$ & & $1.31(0.81-2.12)$ \\
\hline $\mathbf{5 0 - 5 3 5 k}$ & $1.11(0.75-1.65)$ & & $1.50(0.97-2.32)$ \\
\hline $\mathbf{1}$ or More ADL & $1.17(0.87-1.57)$ & & $1.06(0.79-1.41)$ \\
\hline $\mathbf{1}$ or More IADL & & $1.63(1.21-2.21)^{*}$ & & $1.92(1.45-2.54)^{*}$ \\
\hline $\begin{array}{l}\text { Geriatric } \\
\text { Conditions }\end{array}$ & $1.02(0.91-1.13)$ & & $1.05(0.95-1.17)$ \\
\hline Uses Insulin & & $1.19(0.92-1.54)$ & & $1.01(1.00-1.02)^{*}$ \\
\hline TIBI & & $1.02(1.01-1.02)^{*}$ & & \\
\hline
\end{tabular}

†Process of Care measures include HbA1c test, urine test, eye exam, aspirin counseling, and diabetes education $(0=0-2,1=3-5)$, *Significant $\mathrm{P}$-Value

Figure 1. Cox Proportional Hazards Regression. Figure 1 reflects the unadjusted survival probability in years of older adults with diabetes in this sample. 


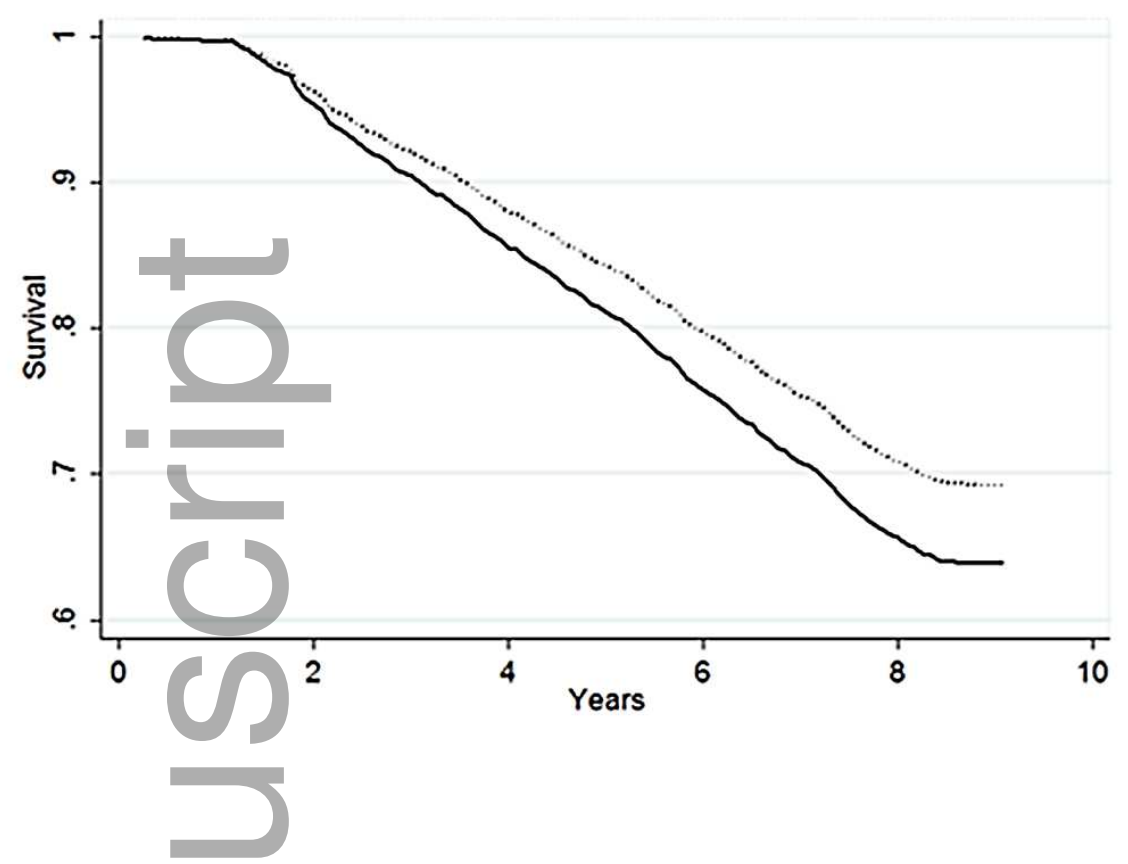

Figure 1 Legend

Black Line $=0.2$ Process of Care Measures Black Dots $=3.5$ Process of Care Measures

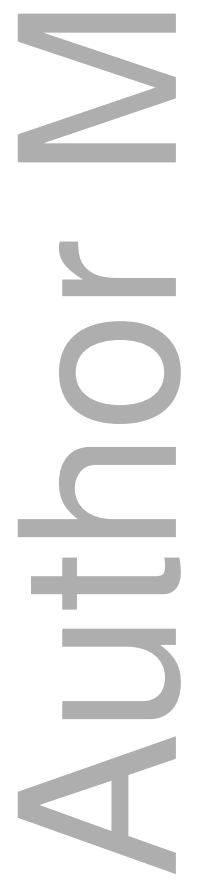

This article is protected by copyright. All rights reserved 
Figure 2: Missing flowchart. Figure 2 reflects flow of data from the HRS core interview wave 2002 to final analytic sample.

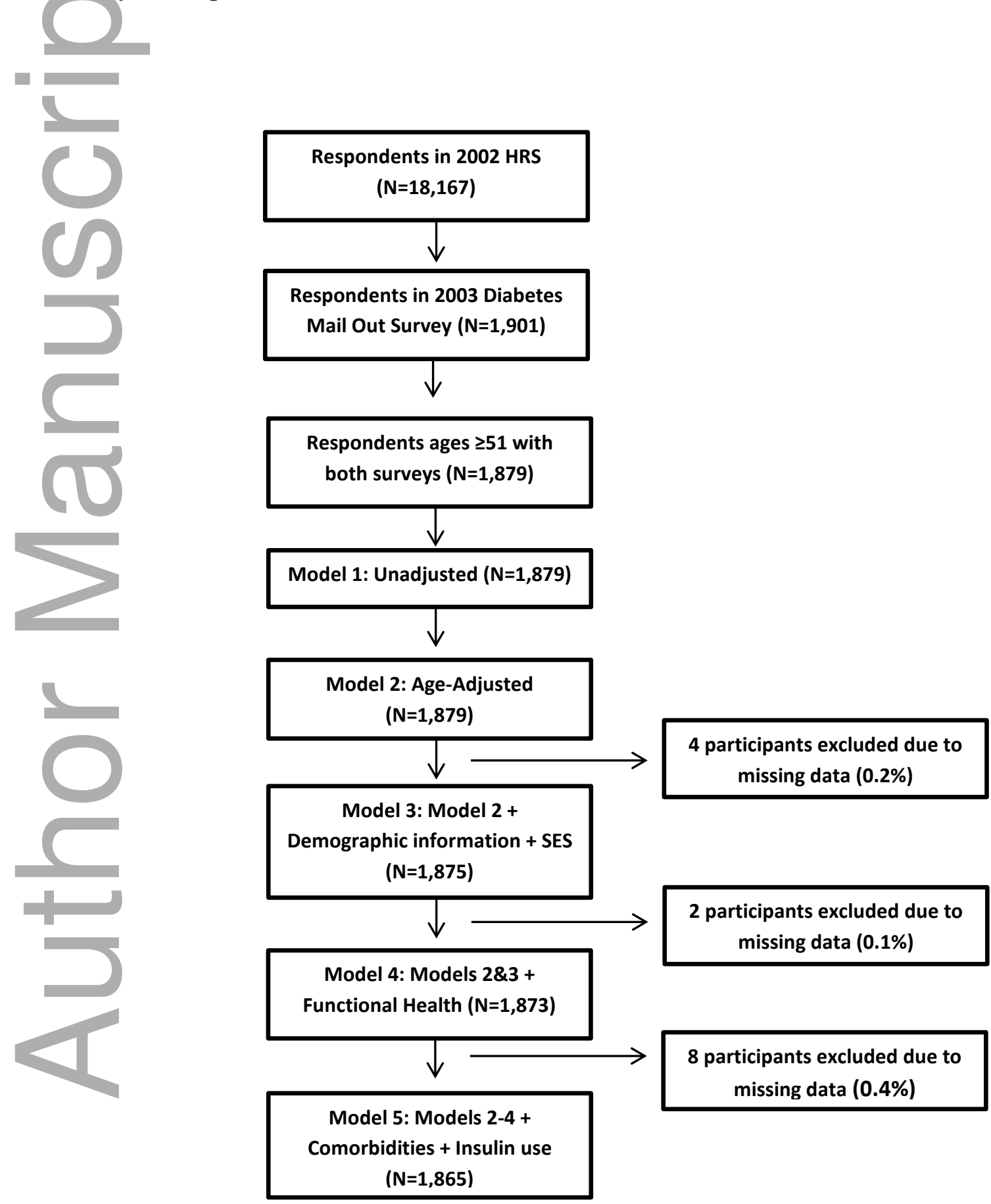

